\title{
Endovascular Treatment of a "Blister- like" Aneurysm of the Internal Carotid Artery
}

\author{
P.D. McNeely, D.B. Clarke, B. Baxter, R.A. Vandorpe, I. Mendez.
}

\begin{abstract}
Backgound: "Blister-like" aneurysms of the supraclinoid internal carotid artery have recently been recognized as having unique pathological and clinical features. Little is known regarding their optimal treatment modality. Methods: We report a case of a "blister-like" aneurysm of the internal carotid artery treated with Guglielmi detachable coil (GDC) embolization. Case Report: A 55year-old man presented with a Hunt \& Hess grade II subarachnoid hemorrhage. Computed tomography revealed diffuse subarachnoid blood. Cerebral angiography demonstrated a broad-based bulge on the medial wall of the right distal internal carotid artery. The patient was taken to the operating room and underwent a right pterional craniotomy and wrapping of this unclippable aneurysm. On postoperative day 11, he developed signs of vasospasm, and repeat angiography showed remarkable growth of the aneurysm. The aneurysm was believed to be amenable to endovascular therapy and was treated by GDC embolization. The patient recovered well and remained neurologically intact on follow-up examinations. Repeat cerebral angiography was performed three and nine months following his initial presentation and revealed a significant aneurysm neck remnant. This neck remnant was treated by repeat GDC embolization 13 months following his subarachnoid hemorrhage. Conclusions: "Blister-like" aneurysms of the internal carotid artery are important to recognize and are difficult to manage using traditional surgical approaches. Early repeated cerebral angiography is indicated and, where appropriate, endovascular therapy should be considered in the management of these patients.
\end{abstract}

RÉSUMÉ: Traitement endovasculaire d'un anévrisme de la carotide interne ayant la forme d'une phlyctène. Introduction: On reconnaît depuis peu que les anévrismes de la carotide interne ayant la forme d'une phlyctène ont des caractéristiques anatomopathologiques et cliniques uniques. On connaît peu de choses en ce qui a trait au traitement optimal de ces anévrismes. Méthodes: Nous rapportons un cas d'anévrisme de la carotide interne ayant la forme d'une phlyctène, traité par embolisation d'une spire détachable de Guglielmi (SDG). Histoire de cas: Un homme âgé de 55 ans a consulté pour une hémorragie sous-arachnoïdienne de Hunt \& Hess de grade II. Une tomographie assistée par ordinateur a montré un saignement sousarachnoïdien diffus. L'angiographie cérébrale a révélé une tuméfaction à base large sur la paroi médiale de la partie distale de la carotide interne droite. Le patient a été conduit en salle d'opération où l'on a procédé à une crâniotomie ptérional droite et à un enveloppement de cet anévrisme impossible à clipper. Au jour 11 en postopératoire, il a développé des signes de vasospasme et une seconde angiographie a montré une croissance importante de l'anévrisme. On a estimé que cet anévrisme était traitable par thérapie endovasculaire et on a procédé à une embolisation d'une SDG. Le patient a bien récupéré, sans séquelle neurologique. Des angiographies de contrôle ont été faites trois et neuf mois après l'examen initial et ont révélé un collet anévrismal résiduel important. Ce collet résiduel a été traité par une seconde embolisation d'une SDG 13 mois après l'hémorragie sous-arachnoïdienne. Conclusions: Il est important de diagnostiquer les anévrismes de la carotide interne ayant la forme d'une phlyctène. Ces anévrismes sont difficiles à traiter par les approches chirurgicales traditionnelles. Il est indiqué de répéter précocement l'angiographie cérébrale et on doit considérer le traitement endovasculaire chez ces patients lorsque c'est approprié.

Can. J. Neurol. Sci. 2000; 27: 247-250

Aneurysms of the distal internal carotid artery which are unrelated to an arterial bifurcation have been labeled "blisterlike" aneurysms. These are a rare type of aneurysm, which have been found to comprise 0.4 to $1.4 \%$ of all aneurysms. ${ }^{1,2,3}$ It is important to recognize this type of aneurysm given their very fragile nature, ${ }^{2,4}$ high rate of intraoperative rupture, ${ }^{1}$ and tendency to progress in size over a short period of time. ${ }^{1}$ Various surgical and endovascular approaches have been described for the treatment of blister-like aneurysms; however, the optimal treatment strategy remains uncertain. We report treatment of this type of aneurysm by Guglielmi detachable coil (GDC) embolization.

\section{CASE RePOrT}

A 55-year-old self-employed carpenter experienced sudden onset of a severe headache while working on the roof of his house. He was initially taken to his local hospital and subsequently referred to our

From Divisions of Neurosurgery (PDM, DBC, IM) and Neuroradiology (BB, RAV), Queen Elizabeth II Health Sciences Centre, Dalhousie University, Halifax, Nova Scotia, Canada.

ReCeived DeCEmber 7, 1999. ACCePted in finAl Form May 18, 2000. Reprint requests to: David B. Clarke, Division of Neurosurgery, Queen Elizabeth II Health Sciences Centre, 1796 Summer St., Room 3807, Halifax, Nova Scotia, Canada B3H 3 A7 


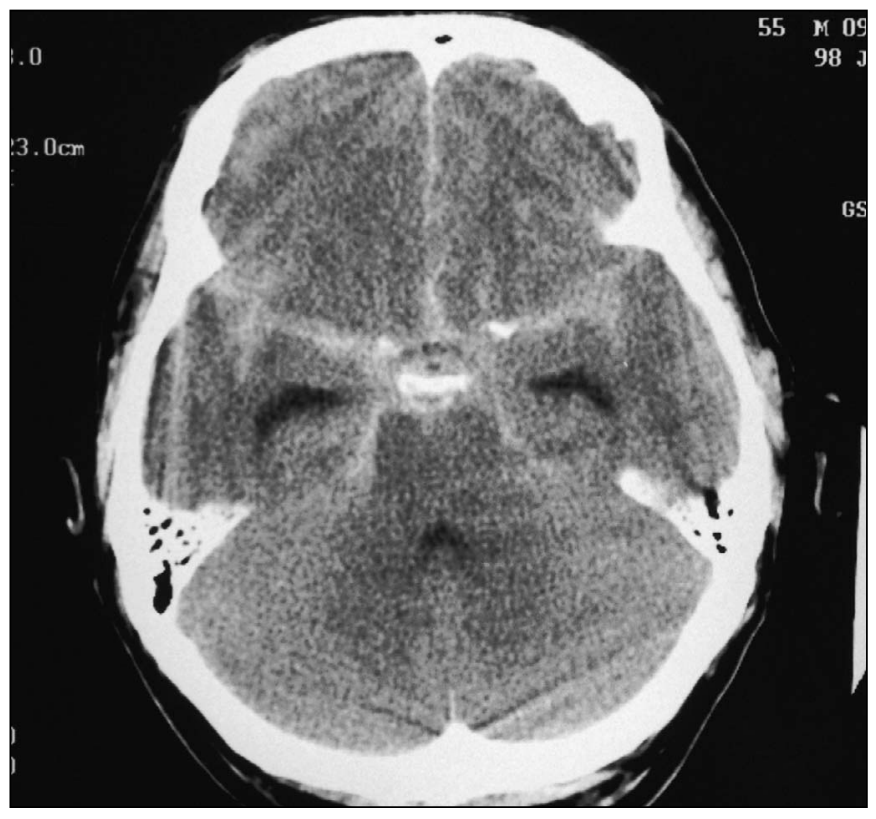

Figure 1: Axial unenhanced CT scan obtained at the time of presentation. This study reveals mild dilatation of the temporal horns and diffuse subarachnoid blood in the suprasellar cistern, as well as in the interhemispheric and Sylvian fissures.

centre. His past medical history was unremarkable, and he was on no medications. Family history was negative for cerebral aneurysms. Physical examination on admission revealed stable vital signs. He was alert and fully oriented but complaining of a severe headache. His neurological examination was normal. Computed tomography (CT) of

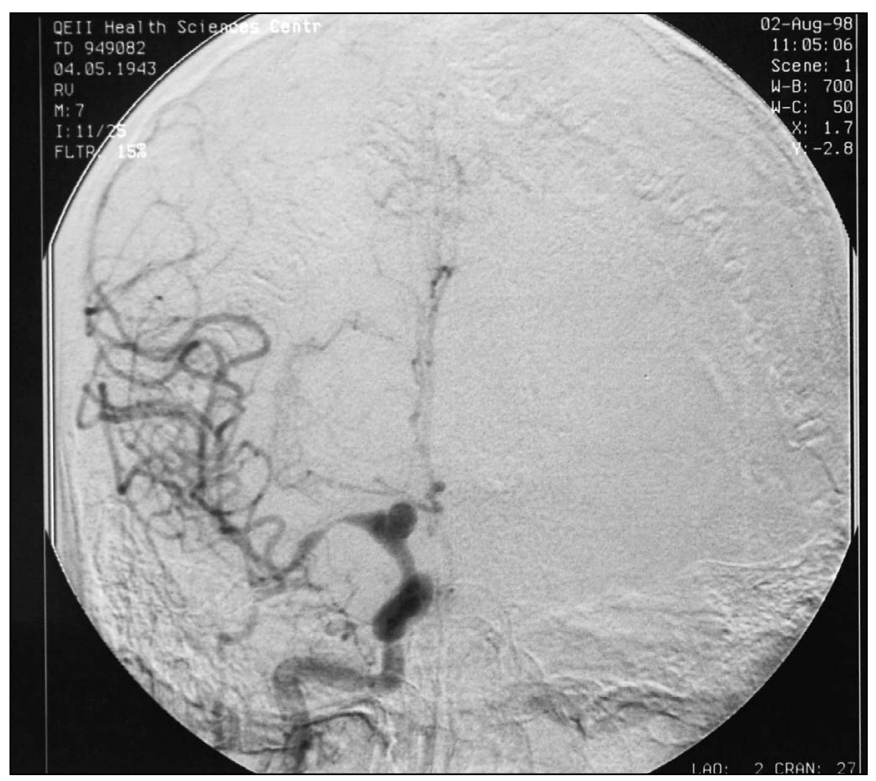

Figure 3: Digital subtraction angiogram, right internal carotid artery injection, anteroposterior view, obtained 10 days postoperatively. This study reveals moderately severe vasospasm of the M1 segment of the middle cerebral artery and significant growth of the internal carotid artery aneurysm.

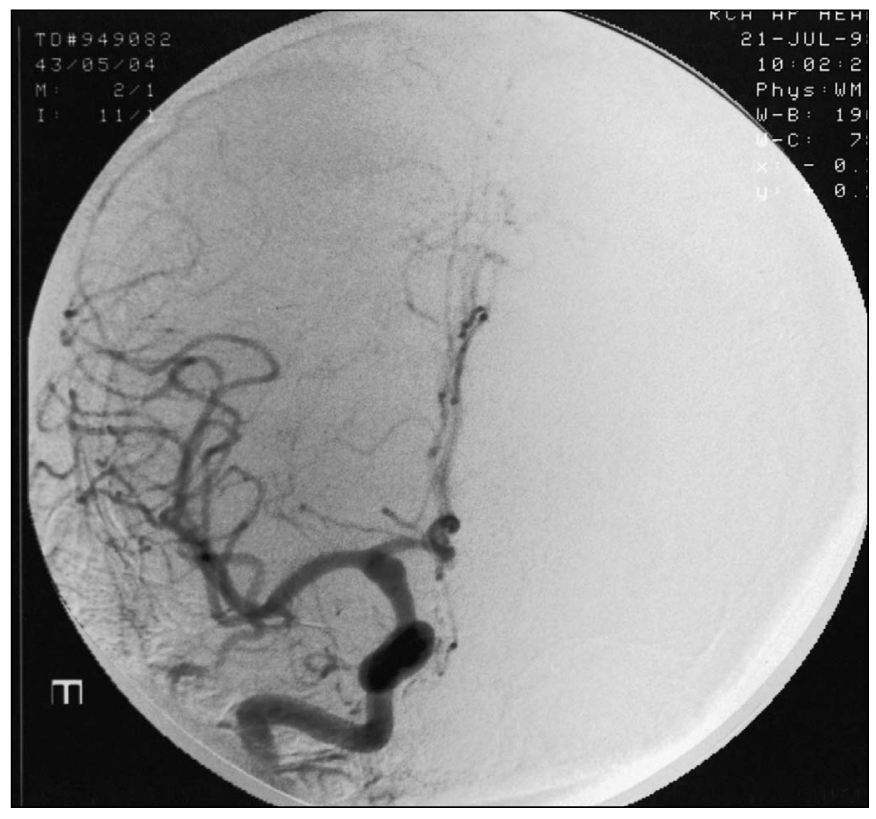

Figure 2: Digital subtraction angiogram, right internal carotid artery injection, anteroposterior view, obtained the day following the patient's admission. This study demonstrates a subtle dilatation on the medial aspect of the distal internal carotid artery.

his head revealed diffuse subarachnoid blood with early signs of hydrocephalus (Figure 1).

Cerebral angiography the following morning did not show a definite aneurysm. It did, however, demonstrate a smooth, bulbous dilatation of the right internal carotid artery distal to the origin of the posterior

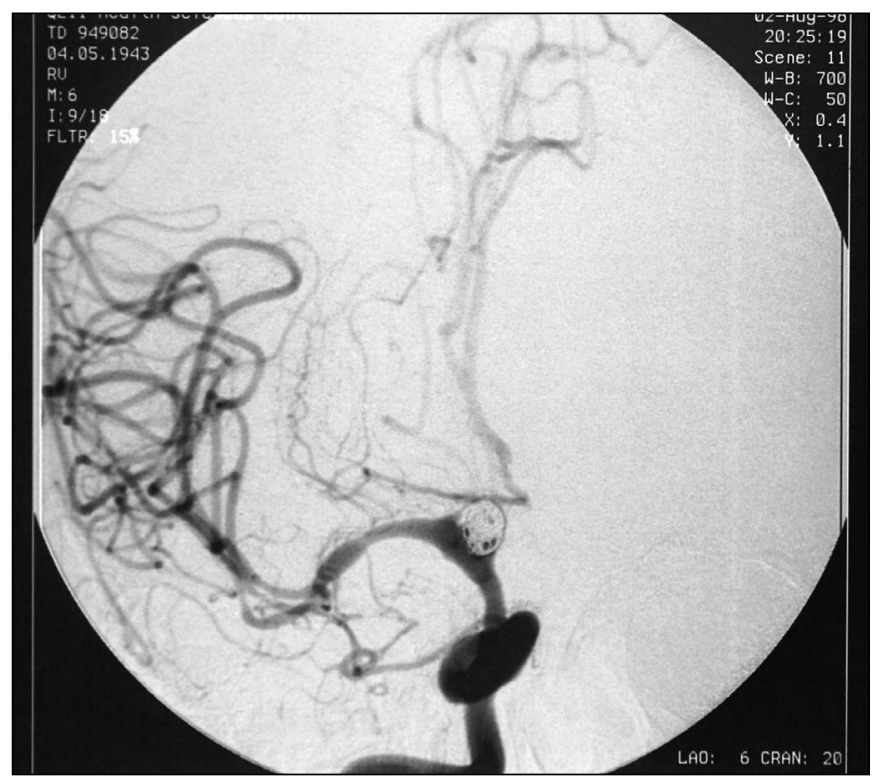

Figure 4: Digital subtraction angiogram, right internal carotid artery injection, anteroposterior view, obtained following endovascular GDC embolization of the internal carotid artery aneurysm. This study shows obliteration of the body of the aneurysm with loose coil loops packing the neck region. 


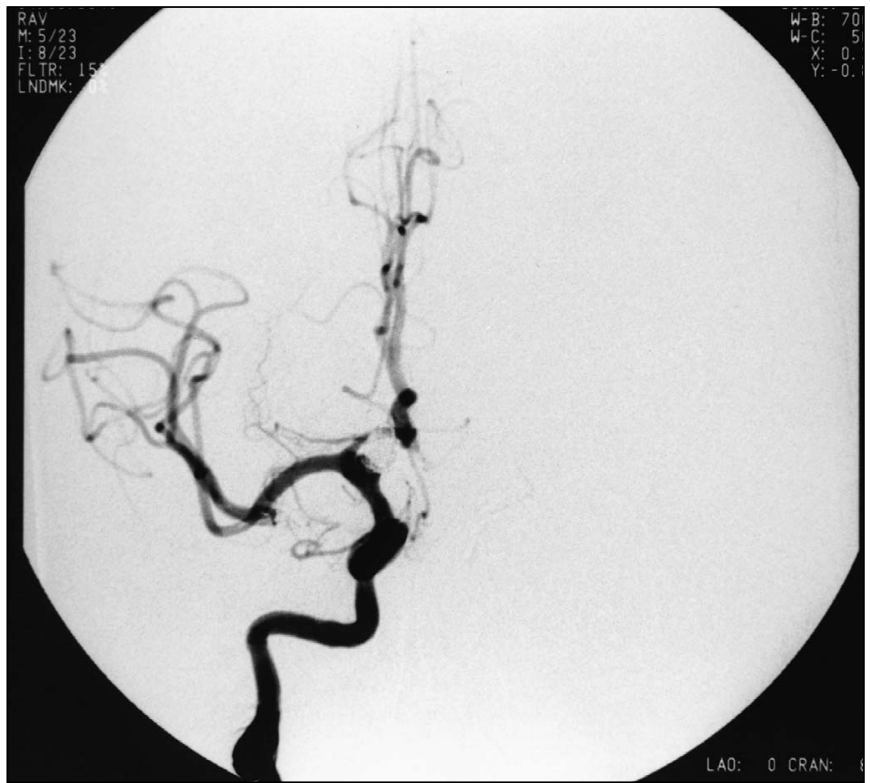

Figure 5: Digital subtraction angiogram, right internal carotid injection, anteroposterior view, obtained following repeat GDC embolization of the "blister-like" aneurysm 13 months after the patient's initial presentation. This study demonstrates improved obliteration of the aneurysm with a small amount of contrast filling in the neck region.

communicating artery (Figure 2). On this first study, the anterior communicating artery complex was not well-visualized and, therefore, the angiogram was repeated the following day. Again, angiography revealed a shallow dilatation of the medial aspect of the distal right internal carotid artery beyond the origin of the posterior communicating artery. It also showed that the anterior communicating artery complex was normal. Based on this information, and suspecting a poorly visualized distal internal carotid artery aneurysm as the cause of the subarachnoid hemorrhage, it was decided to take the patient to the operating room for surgical exploration. At the time of the operation, three days following admission, a broad-based, fragile-appearing irregular medial wall of the distal right internal carotid artery lateral to the optic nerve and chiasm junction was identified. There was no clippable aneurysm. The abnormality identified on the medial wall of the distal internal carotid artery was wrapped with gauze. Circumferential wrapping of the artery was not possible due to the take-off of the posterior communicating and anterior choroidal arteries directly opposite the irregular medial wall.

Postoperatively, the patient was stable until the tenth day, when a left hemiparesis developed, which was believed to be due to vasospasm. A CT scan was done at this time and did not show any acute changes when compared with other postoperative scans. Repeat angiography confirmed vasospasm but also showed remarkable growth of the aneurysm (Figure 3). The vasospasm was treated by angioplasty of the M1 segment of the right middle cerebral artery. The aneurysm was felt to be amenable to endovascular therapy and was thus treated by GDC embolization. Three coils were used: a GDC-10 regular $7 \mathrm{~mm} \times 25 \mathrm{~cm}$, a GDC-10 regular $6 \mathrm{~mm} \times 10 \mathrm{~cm}$, and a GDC-10 soft $2 \mathrm{~mm} \times 6 \mathrm{~mm}$. Following this procedure, the aneurysm was $90 \%$ obliterated with a few loose coil loops packing the neck region (Figure 4). The patient tolerated this procedure well and was finally discharged home approximately four weeks following his admission. He has remained neurologically intact on follow-up clinical examinations. Angiography at three and nine months demonstrated obliteration of the body of the aneurysm and compaction of the coil loops with contrast filling between the GDC coils at the base of the aneurysm. It was decided to treat the residual aneurysm with repeat GDC embolization 13 months following his initial presentation. Three coils were used (one GDC-10 regular $4 \mathrm{~mm}$ x $8 \mathrm{~cm}$ and two GDC-10 soft $3 \mathrm{~mm} \times 6 \mathrm{~cm}$ coils) to treat the residual aneurysm (Figure 5). The patient tolerated the procedure well and remains neurologically intact. Subsequent angiogram three months later (16 months after the subarachnoid hemorrhage) shows no change in the angiographic appearance of the aneurysm. Further angiographic followup is planned in one year.

\section{Discussion}

Blister-like aneurysms are known to occur in the supraclinoid portion of the internal carotid artery. Aneurysms arising from this location were first described by Sundt and Murphey, ${ }^{5}$ and subsequently by Yasargil. ${ }^{6}$ These lesions were first designated as "blister-like" aneurysms in the English literature by Shigeta et al. in $1992 .^{3}$ The aneurysms are thin-walled, broad-based, and often have no identifiable neck at the time of presentation. Ishikawa et al. ${ }^{7}$ documented the pathology in a case of fatal subarachnoid hemorrhage from a blister-like aneurysm. They observed that the aneurysm was associated with arteriosclerosis of the neighboring carotid wall. They also reported abrupt termination of the internal elastic lamina at the border between the normal and sclerotic carotid wall. The dome of the aneurysm was found to be composed of fibrinous tissue and adventitia while the usual collagenous layer was absent. Dissection and infiltration of the arterial wall by inflammatory cells were also absent. Other authors have also noted an association between arteriosclerosis and this type of aneurysm. ${ }^{8,9,10}$ Abe et al. ${ }^{1}$ have suggested that the absence of the collagenous layer may explain the high intraoperative rupture rate associated with these aneurysms.

It is important to recognize the angiographic appearance of blister-like aneurysms. The abnormalities on angiography may be subtle. Particular attention must be paid to the distal internal carotid artery when a patient with a subarachnoid hemorrhage is not found to have any obvious aneurysms. In our case, the initial angiogram failed to demonstrate a definite aneurysm. Repeat angiography the following day was interpreted as showing only a diffuse dilatation of the distal right internal carotid artery. It is possible that missed blister-like aneurysms are among the causes of angiographically occult subarachnoid hemorrhage.

Rapid growth of these aneurysms over a short period of time has been reported by Abe et al. ${ }^{1}$ In this series, growth of the aneurysm had occurred at intervals of 14 to 17 days on repeat angiography, often assuming a saccular appearance. Shigeta et al. ${ }^{3}$ also documented rapid growth of such aneurysms which were not visualized during the first angiogram. In our patient, remarkable progression from a subtle bulging abnormality to a saccular aneurysm was angiographically documented over an 11-day interval, despite surgical wrapping. This pattern of rapid growth attests to the fragile and unique nature of blister-like aneurysms.

Various treatment options have already been reported for blister-like aneurysms. Direct surgical clipping, ${ }^{5}$ including wrapping of the lesion with gauze, muscle, fascia, cellulose fabric, and Gore-Tex ${ }^{1}$ have been described. Surgical trapping of the internal carotid artery for blister-like aneurysms has also been reported. ${ }^{2}$ Others have described sacrificing the internal carotid artery by endovascular occlusion with or without bypass surgery. ${ }^{1}$ 
The increased incidence of intra-operative rupture ${ }^{3,4}$ and rapid rate of progression of blister-like aneurysms are among the difficulties encountered in the management of these lesions. Open surgery can be difficult and may not definitively treat these aneurysms. Endovascular treatment may also be difficult due to the presence of a wide neck. Furthermore, the fragile nature of blister-like aneurysms raises concerns of aneurysmal rupture during GDC embolization. Early repeat angiography is important and, in our patient, recognizing progression of the blister-like aneurysm to a saccular form prompted consideration of endovascular therapy. This strategy avoided a repeat craniotomy and its associated morbidity, and allowed successful treatment of this fragile aneurysm. Further follow-up angiography will provide documentation as to the long-term stability of this endovascularly treated blister-like aneurysm but these early results are encouraging. To our knowledge, GDC coiling has never been reported for blister-like aneurysms, and our experience would suggest that this treatment modality should be considered for the treatment of patients who have these aneurysms.

\section{Conclusions}

In summary, we believe that vigilance is required to correctly identify blister-like aneurysms of the internal carotid artery, particularly in the setting of subarachnoid hemorrhage with a cerebral angiogram which fails to demonstrate a definite aneurysm. Early repeat angiography may be especially important in these patients, given the potential for rapid growth of blister- like aneurysms. Endovascular GDC embolization is an appropriate treatment modality to consider when these aneurysms assume a saccular configuration.

\section{REFERENCES}

1. Abe M, Tabuchi K, Yokoyama H, Uchino A. Blood blister-like aneurysms of the internal carotid artery. J Neurosurg 1998; 89: 419-424.

2. Redekop GJ, Woodhurst B. Unusual aneurysms of the distal internal carotid artery. Can J Neurol Sci 1998; 25: 202-208.

3. Shigeta H, Kyoshima K, Nakagawa F, Kobayahsi S. Dorsal internal carotid artery aneurysms with special reference to angiographic presentation and surgical management. Acta Neurochir (Wien) 1992; 119: 42-48.

4. Nakagawa F, Kobayachi S, Takemae, Sugita K. Aneurysms protruding from the dorsal wall of the internal carotid artery. J Neurosurg 1986; 65: 303-308.

5. Sundt TM, Murphey F. Clip-grafts for aneurysm and small vessel surgery. J Neurosurg 1969; 31: 59-71.

6. Yasargil MG: Internal carotid artery aneurysms. In: Yasargil MG, Microneurosurgery. Stuttgart: George Thieme Verlag, 1984, Vol. 2: $58-59$

7. Ishikawa T, Nakamura N, Houkin K, Nomura M. Pathological consideration of a "blister-like" aneurysm at the superior wall of the internal carotid artery: case report. Neurosurgery 1997; 40: 403-406.

8. Stehbens WE. The pathology of intracranial arterial aneurysms and their complications. In: Fox JL ed. Intracranial Aneurysms. New York/Berlin/Heidelberg: Springer-Verlag, 1983, Vol 1: 272-357.

9. Stehbens WE. Etiology of intracranial berry aneurysms. J Neurosurg 1989; 70: 823-831.

10. Yoshimoto Y, Ochiai C, Nagai M. Cerebral aneurysms unrelated to arterial bifurcations. Acta Neurochir (Wien) 1996; 138: 958-964. 